\title{
Mental stress in infertility: a tertiary care hospital-based study
}

\author{
Susmita Bhattacharya $^{1}$, Amit Kyal ${ }^{1 *}$, Payel Mondal ${ }^{1}$, \\ Partha Mukhopadhyay ${ }^{1}$, Mrinalini Chowdhury ${ }^{1}$, Debasubhra Mitra ${ }^{2}$
}

\begin{abstract}
${ }^{1}$ Department of Obstetrics and Gynecology, Medical College Kolkata, Kolkata, West Bengal, India
${ }^{2}$ Department of Orthopedics, ESIC Medical College, Joka, West Bengal, India
\end{abstract}

Received: 09 August 2018

Accepted: 04 September 2018

\section{*Correspondence:}

Dr. Amit Kyal,

E-mail: amitkyal@yahoo.com

Copyright: (c) the author(s), publisher and licensee Medip Academy. This is an open-access article distributed under the terms of the Creative Commons Attribution Non-Commercial License, which permits unrestricted non-commercial use, distribution, and reproduction in any medium, provided the original work is properly cited.

\section{ABSTRACT}

Background: Most of the couples suffering from infertility report it to be the most stressful and depressing period of their life, more so if it is a primary infertility. Studies regarding the prevalence and role of infertility-specific stress especially in eastern part of India is very limited. The objective of the present study was to estimate the prevalence of infertility-specific stress and its role in marital adjustment in women diagnosed with infertility.

Methods: It was a cross-sectional study done on 80 married couple diagnosed with infertility (both primary and secondary) over 1 year from July 2016 to June,2017. Dyadic Adjustment Scale (DAS), "semi-structured questionnaire" compiled by the authors and "ICD-10 Classification of Mental and Behavioral Disorders (Clinical Descriptions and Diagnostic Guidelines)" were used for the evaluation. The analysis was done using SPSS (version 16) and Chi-square test.

Results: Around $86 \%$ infertile women and $21 \%$ infertile men were found to suffer from mental stress. Infertility related stress were more in patients with primary infertility than in secondary one. Women mostly (56.5\%) coped with stress by self-blaming whereas men $(58.2 \%)$ by blaming the partner.

Conclusions: Mental stress was significantly associated with infertility. In fact, maladjustment in marital relation caused by the stress adversely affected the conjugal life and thus also the fertility. Proper counselling of both partners might be helpful to solve this problem.

Keywords: Infertility, Mental Stress, Stress

\section{INTRODUCTION}

Infertility is defined as a failure to conceive after 12 months of regular sexual intercourse without contraception (World Health Organization 2015). ${ }^{1}$ In developed countries, this affects $15 \%$ of couples and $25 \%$ in developing countries; approximately one in four to six couples encounters difficulty in conceiving (World Health Organization2016). ${ }^{2}$ In 2010 the prevalence of infertility was similar to that in 1990 in most countries, reflecting that the issue has not lessened over time. ${ }^{3}$ In the International Conference of Infertility in Bangkok in 1998, infertility was considered as a global health problem with physical, psychological and social dimensions. ${ }^{4}$ Contributing factors are categorized are mainly male, female, combined and unexplained. Male factors such as low sperm count or decreased sperm motility account for $30 \%$ of cases, and female factors such as absence of ovulation, tubal blockage or premature menopause constitute another $30 \%$ of cases. Another $30 \%$ of cases are attributable to combinations of male and female factors. The remaining $10 \%$ of infertility cases remain unexplained or idiopathic for both partners. ${ }^{5}$

A diagnosis of infertility represents a life crisis for affected couples. Common individual reactions include 
anger, sadness, a feeling of loss of control, stress, anxiety, depression, altered self-esteem, guilt, blame and shame. ${ }^{6}$ Infertility complicates the life of infertile couples with various social, psychological, physical and financial stresses. Infertile couples blame their partners upon a diagnosis of infertility. They become dissatisfied with their marital life due to a lack of joyous moments, decreases in sexual desire, pleasure and satisfaction. ${ }^{7}$ Artificial reproductive treatment becomes the last resort for those who have difficulty achieving pregnancy, but the treatment is often expensive, complex and invasive and has a low success rate, around $30-40 \%$ depending on the age of the female partner, inflicting considerable distress and financial pressure on couples. ${ }^{8}$

Over the ages there are tremendous changes in family values, but parenthood has still been an undeniable importance for women and men. Infertility carries much social stigma in many communities, leading to many social problems for infertile couples. In fertility coincides with numerous psychological and social challenges, especially for women, and it affects all aspects of infertile couples' life, including their emotional, psychological, physical and social performances. ${ }^{9}$

In view of the significant psychological distress in infertile couples, several psychosocial interventions have been developed to offer support, but these are mostly limited to Western countries. ${ }^{10}$ Psychosocial intervention is defined as any intervention that addresses the psychological or social needs of the patient and can be delivered in any format, including group or individual interventions. $^{11}$ A wide range of psychosocial interventions for infertile couples have been developed, including education programmes, coping skills training, support groups, sexual counselling, couple therapy, cognitive-behavioural therapy and mind-body interventions. But studies in this aspect in Asian countries especially in India are sparse. Infertile couples' stress and stressors should be identified. Evaluation of these problems is a prerequisite to plan effective supportive interventions. The objectives of the present study were to estimate the prevalence of mental stress in infertility and to explore the association of mental stress with infertility.

\section{METHODS}

It was a Cross-Sectional qualitative study which was based on a content analysis approach of semi-structured questionnaire. Infertile couples seeking reproductive treatments in OPD of Medical College, Kolkata were recruited in the study over 1year period from July 2016 to June 2017. Infertile couples were selected through purposive sampling method with maximum variation, including different causes of infertility, different types of infertility (primary and secondary), a wide range of age, at different stages of infertility treatment and different durations of infertility. The inclusion criteria for infertile couples were as follows: at least one year after marriage, confirmation of their infertility by the specialist, Indian nationality and willingness to participate in the study whereas the couples with history of mental disorders during last 12 months and those who had physical disabilities to express their feelings and experiences were excluded from the study. A couple-based dyadic approach was applied for the interview. In depth interview done using semi-structured questionnaire. Perceived stress scale and Dyadic Adjustment Scale was used to evaluate mental stress. The Perceived Stress Scale (PSS) is the most widely used psychological instrument for measuring the perception of stress. It is a measure of the degree to which situations in one's life are appraised as stressful. PSS is commonly implemented using the 10item form; every item scoring 0 to 4.PSS scores are obtained by reversing responses (e.g., $0=4,1=3,2=2$, $3=1$ and $4=0$ ) to the four positively stated items (items $4,5,7$, and 8) and then summing across all scale items. Higher PSS scores were associated with greater vulnerability to stressful life-event-elicited depressive symptoms Relevant demographic informations like age, gender, educational profile, family structure, substance abuse, no of previous children were also studied. The interview data were analyzed using conventional content analysis method. All participants were interviewed in one or two sessions lasting approximately 20 to 60 minutes.

This study was confirmed by the Ethical Committee of Medical College, Kolkata. Also, prior to interviews, participants were made aware of the objectives of the research and an informed consent was obtained. Oral and written permissions were obtained from them for recording their interviews and they were assured that the gathered data would only be used for research objectives. It was also announced to the participants that they could withdraw the research anytime they wish, and their information would remain confidential during and after the research.

\section{RESULTS}

Eighty infertile couples were initially recruited for the study out of which 69 women and 17 men had mental stress there by prevalence of stress in women was $86.25 \%$ and in men was $21.25 \%$.

Further evaluation of the women and men with stress were carried out in respect to type of infertility, educational profile, coping strategy with stress, substance family and family structure.

Table 1: Association with type of infertility.

\begin{tabular}{|lll|}
\hline $\begin{array}{l}\text { Presence of } \\
\text { stress }\end{array}$ & $\begin{array}{l}\text { Primary } \\
\text { infertility }\end{array}$ & $\begin{array}{l}\text { Secondary } \\
\text { infertility }\end{array}$ \\
\hline Women $(\mathrm{n}=69)$ & $51(73.9 \%)$ & $18(26.09 \%)$ \\
\hline Men $(\mathrm{n}=17)$ & $12(70.59 \%)$ & $5(29.41 \%)$ \\
\hline
\end{tabular}

In both women and men majority of the patients suffering from stress were having primary infertility. Out of females $73.9 \%$ and males $70.59 \%$ were suffering from 
primary infertility. Definitely people who never conceived were more vulnerable to stress socially and emotionally.

The study shows that fair percentage of people having stress with infertility had education at least upto high school both in women $(43.48 \%)$ and men $(47.06 \%)$. Even $21.74 \%$ of women and $17.65 \%$ of men had highersecondary education.

Table 2: Educational profile.

\begin{tabular}{|lll|}
\hline Education & $\begin{array}{l}\text { Infertile } \\
\text { women with } \\
\text { stress }(\mathrm{n}=69)\end{array}$ & $\begin{array}{l}\text { Infertile men } \\
\text { with stress } \\
(\mathrm{n}=17)\end{array}$ \\
\hline Illiterate & $4(5.8 \%)$ & $2(11.76 \%)$ \\
\hline High school & $30(43.48 \%)$ & $8(47.06 \%)$ \\
\hline Higher secondary & $15(21.74 \%)$ & $3(17.65 \%)$ \\
\hline Graduate & $12(17.39 \%)$ & $3(17.65 \%)$ \\
\hline Post graduate & $8(11.59 \%)$ & $1(5.88 \%)$ \\
\hline
\end{tabular}

Last but not the least $11.59 \%$ of women and $5.88 \%$ of men had post-graduation.

It reflects education could not be a barrier to prevent stress rather with increased education probably the age of marriage had risen which could be a contributory factor related to infertility.
Table 3. Coping with stress.

\begin{tabular}{|lll|}
$\begin{array}{l}\text { Coping with } \\
\text { stress }\end{array}$ & $\begin{array}{l}\text { Infertile } \\
\text { women with } \\
\text { stress }(\mathrm{n}=69)\end{array}$ & $\begin{array}{l}\text { Infertile men } \\
\text { with stress } \\
(\mathrm{n}=17)\end{array}$ \\
\hline Self-blaming & $39(56.52 \%)$ & $1(5.88 \%)$ \\
\hline $\begin{array}{l}\text { Ignoring the fact } \\
\text { Busy in other jobs }\end{array}$ & $13(18.84 \%)$ & $4(23.53 \%)$ \\
\hline Blaming partner & $3(4.35 \%)$ & $10(58.82 \%)$ \\
\hline
\end{tabular}

The study shows that women used to cope with the stress mainly $(56.52 \%)$ by blaming themselves where as men used to blame the partner in $58.82 \%$. Other coping strategies used by the patients were ignoring the fact in $18.84 \%$ of women and $23.53 \%$ of men and getting busy in other jobs in $20.29 \%$ and $11.77 \%$ of women and men respectively.

Table 4: Substance abuse.

\begin{tabular}{|lll|}
$\begin{array}{ll}\text { Substance } \\
\text { abuse }\end{array}$ & $\begin{array}{l}\text { Infertile women } \\
\text { with stress }(n=69)\end{array}$ & $\begin{array}{l}\text { Infertile men with } \\
\text { stress }(n=17)\end{array}$ \\
\hline Present & $9(13.04 \%)$ & $14(82.35 \%)$ \\
\hline Absent & $60(89.96 \%)$ & $3(17.65 \%)$ \\
\hline
\end{tabular}

Table 5 shows that most of the men with stress and infertility $(82.35 \%)$ had substance abuse in various forms like alcohol, tobacco, and cigarettes etc. where the ratio is negligible in case of women.

Table 5: Type of family.

\begin{tabular}{|llll|l|}
\hline Type of family & Infertile women with stress $(\mathbf{n = 6 9 )}$ & $\%$ & Infertile men with stress $(\mathbf{n = 1 7})$ & $\%$ \\
\hline Joint & 51 & 73.91 & 11 & 64.71 \\
\hline Nuclear & 18 & 26.09 & 6 & 35.29 \\
\hline Total & 69 & 100 & 17 & 100 \\
\hline
\end{tabular}

Only $13.04 \%$ of women with stress had substance abuse. Perhaps substance dependence and forgetting the fact was another coping strategy in men with infertility and stress. The above table shows that majority of the couple having mental stress in infertility were living in joint family. As high as $73.91 \%$ of women and $64.71 \%$ of men with stress and infertility were living in a joint family. In-laws pressure, different social, cultural and religious beliefs, comments and taunting by other family members and relatives specially those who have children might contribute to it.

\section{DISCUSSION}

Infertility is a very stressful situation and can cause a multitude of adverse social and psychological consequences including aggravated mental distress. Among the couple, an increased level of stress is seen more in the female counterpart, which endangers their mental health. Having a child is often considered as proof of manhood/woman hood; a symbol of fruitfulness of life and the child is a precious heir to continue the family name. Hence infertility becomes a social stigma, which has a devastating effect on women's health. In many traditional cultures and especially in India, there is a relatively higher pressure on women to bear a child and she is often the one who is ostracized and blamed for not creating progeny. ${ }^{12}$ The social consequences of infertility mainly affect the women, although men are equally responsible for infertility. ${ }^{13}$ Bayley TM and others showed in their study that negative attitude and stress appraisal was much more in women. ${ }^{14}$ Present study also shows that prevalence of stress in women (86.25\%) was almost 4times than that of men $(21.25 \%)$. In support to present study, another study conducted by Peterson et al in Denmark taking total of 1049 men and 1131 women having infertility to examine the severe depressive symptoms in women and men showed that severe 
depressive symptoms were reported in men $4.3 \%$ and $11.6 \%$ in women. ${ }^{15}$ Present study found the prevalence of stress was much higher in those suffering from primary infertility than secondary infertility. In contrast to it there was a higher prevalence of sexual dysfunction in form of decreased sexual desire, orgasm, and satisfaction in women with secondary infertility compared with primary infertile women in the study of Ugur Keskinet al in Turkey. ${ }^{16}$ Another study by Aytac Sahin et al the frequency of the depression and erectile dysfunction seen in the patients with secondary infertility was seen significantly higher than the patients with primary infertility. ${ }^{17}$

This study showed infertile couple with stress had at least education up to high school. Wischmann $\mathrm{T}$ et al in their study showed high educational profile had specific higher prevalence of idiopathic infertility. ${ }^{18}$

Present study found that majority of women used to blame themselves where male used to blame the partner, that's how they coped up with stress. In the study by B.D. Peterson et al one of the most consistent findings in the study by was the strength of the relationship between escape/avoidance coping and infertility stress and marital adjustment. ${ }^{19}$ In their study they found that women proportionately engaged in a greater degree of confrontative coping, accepting responsibility, seeking social support and escape/avoidance whereas For both men and women, seeking social support was the most frequently used form of coping relative to all others, whereas accepting responsibility was the coping strategy used least in comparison to all others. On the contrary, Ozkan $\mathrm{S}$ et al showed infertile men and women use similar coping strategies and have similar coping scores in all subscales (Self-confident, Desperate, Obedient, Optimistic, Social Support Seeking). ${ }^{20}$

We found substance abuse was significantly high in male with stress and infertility mainly in the form of tobacco and alcohol. Studies related to prevalence of substance abuse as a dependency or to get relief of infertility stress are sparse. But Andrea Sansone et al showed that despite the lack of solid evidence from interventional studies, it is clear that smoking, alcohol use and recreational drug consumption somehow impairs male fertility, with possible synergistic, rather than addictive, effects. ${ }^{21}$ Impairments in spermatogenesis and sperm parameters as well as increased DNA methylation and oxidative stress observed in humans and animal models are almost alike. It also adversely affects the endocrine control of reproductive and sexual function have been reported in clinical and experimental studies.

\section{Does infertility cause stress?}

Children are building blocks for maintaining family bond and help bridge the generation gap. So, infertility is regarded as a curse in different cultures especially in India. Couples sometime blame the God for their barren life. Thus, it becomes a religious stress too along with a social stress. In addition, certain religions forbid or discourage some forms of infertility treatment. These profoundly affects the stress of the infertile couple sloughing against the entire stigma and opting to try infertility evaluation and treatment. Infertility is a great deal of financial stress too. A huge amount of money is required for the infertility treatment and tests especially with the advent of modern assisted reproductive techniques such as IVF, which require expertise and advanced technology, the expenses incurred can be huge. The couples often run from Centres to Centres often taking loans, mortgaging property, in the hope of having a baby but ultimately fails leading to huge amount of stress.

Does stress cause infertility?

We all know that increasing stress levels and certain mental disorders like anorexia significantly alters the Hypothalamo-Pituitary-Ovarian axis of the patients which alters the reproductive hormonal milieu of the subjects and can contribute to ovulatory dysfunction and subfertility. Men with stress is often have erectile and coital dysfunction again contributing to subfertility. The stress hormone adrenaline inhibits function of progesterone, which is essential for fertility. Adrenaline also stimulates Pituitary to secrete higher levels of Prolactin which both lowers sex drive and reduces fertility by preventing ovulation. So, whether stress causes infertility or vice versa is still an enigma but definitely it's a vicious cycle causing tremendous psychological pressure on the couples. The limitations of the present study were Small sample size, small duration of study, lack of detailed psychiatric evaluation of patients.

\section{CONCLUSION}

Infertility negatively affects social, personal and marital relations resulting in mental imbalance and stress. Gender inequality, patriarchal society contributes to more sufferings of female than male. A cumulative approach with counselling, social support group, psychotherapy, relaxation techniques like deep breathing exercises and medication should be offered.

Funding: No funding sources

Conflict of interest: None declared

Ethical approval: The study was approved by the Institutional Ethics Committee

\section{REFERENCES}

1. World Health Organization (2015) Infertility Definitions and Terminology. Available at: http://www.who.int/reproductivehealth/topics/infertil ity/definitions/en/.

2. World Health Organization (2016) Global Prevalence of Infertility, Infecundity and 
Childlessness.

Available

at: http://www.who.int/reproductivehealth/topics/infertil ity/burden/en/.

3. Mascarenhas MN, Flaxman SR, Boerma T, Vanderpoel S, Stevens GA. National, regional, and global trends in infertility prevalence since 1990: a systematic analysis of 277 health surveys. PLoS Medicine. 2012;9(12):e1001356.

4. Molid HA, Varaghchi JR. Psychological metaanalysis of the infertility researches in Iran. Iranian J Obstet, Gynecol Infertil. 2012;15(13):26-33.

5. Cousineau TM, Domar AD. Psychological impact of infertility. Best Practice Res Clinical Obstet Gynaecol. 2007;21(2):293-308.

6. Peloquin K, Brassard A. Infertility: a social and spousal reality that needs to be studied. IntegratingScience and Practice. 2013:3,22-6.

7. Jafarzadeh-Kenarsari F, Ghahiri A, ZarghamBoroujeni A, Habibi M. Exploration of the counseling needs ofinfertile couples: a qualitative study. Iran $\mathbf{J}$ Nursing and Midwifery Res.2015;20(5):552-9.

8. Center for Human Reproduction, USA (2015) InVitro Fertilization (IVF). Available at: http://www.centerforhumanreprod.com/services/infer tility-treatments/ivf/success-rates/.

9. Aarts JW, van Empel IW, Boivin J, Nelen WL, Kremer JA, Verhaak CM. Relationship between quality of life and distress in infertility: a validation study of the Dutch Ferti QoL. Hum Reprod. 2011; 26(5):1112-8.

10. Frederiksen Y, Farver-Vestergaard I, Skovgård NG, Ingerslev HJ, Zachariae R. Efficacy of psychosocial interventions for psychological and pregnancy outcomes in infertile women and men: a systematic review and meta-analysis. BMJ open. 2015;5(1):e006592.

11. Chan $\mathrm{CH}, \mathrm{Ng} \mathrm{EH}$, Chan CL, Chan TH. Effectiveness of psychosocial group intervention for reducing anxiety in women undergoing in vitro fertilization: a randomized controlled study. Fertility and Sterility. 2006;85(2):339-46.

12. Shahnooshi M, Karimi Z. [Sociological impact of infertility upon family in Isfahan province] J Soc Sci. 2010;11(4):171-98.
13. Dyer SJ, Abrahams N, Mokoena NE, Van der Spuy ZM. Psychological distress among women suffering from couple infertility in South Africa: a quantitative assessment. Hum. Reprod. 2004;19(7):960-7.

14. Bayley TM1, Slade P, Lashen H.Relationships between attachment, appraisal, coping andadjustment in men and women experiencing infertility concerns. Human Reproduction. 2009;24(11):2827-37.

15. Peterson BD, Sejbaek CS, Pirritano M, Schmidt L. Are severe depressive symptoms associated with infertility-related distress in individuals and their partners? Human Reprod.2013;29(1):76-82.

16. Keskin U, Coksuer H, Gungor S, Ercan CM, Karasahin KE, Baser I. Differences in prevalence of sexual dysfunction between primary and secondary infertile women. Fertil Steril. 2011;96(5):1213-7.

17. Sahin A, Urkmez A, Verit A, Yuksel OH, Verit FF. Psychologic and sexual dysfunction in primary and secondary infertile male patients. Archivio Italiano di Urologia e Andrologia. 2017;89(2):120-4.

18. Wischmann T, Stammer H, Scherg H, Gerhard I, Verres R.Psychosocial characteristics of infertile couples: a study by the 'Heidelberg Fertility Consultation Service'. Hum Reprod. 2001;16(8):1753-61.

19. Peterson BD, Newton CR, Rosen KH, Skaggs GE. Gender differences in how men and women who are referred for IVF cope with infertility stress. Human Reproduction. 2006;21(9):2443-9.

20. Ozkan S, Karabulut A, Oğuz N, Sorkun HC.Coping with the Stress of Infertility. Males Versus Females.J Reprod Med. 2015;60(7-8):339-44.

21. Sansone A, Di Dato C, de Angelis C, Menafra D, Pozza C, Pivonello R, Isidori A, Gianfrilli D. Smoke, alcohol and drug addiction and male fertility. Reproduct Biol Endocrinol. 2018;16(1):3.

Cite this article as: Bhattacharya S, Kyal A, Mondal P, Mukhopadhyay P, Chowdhury M, Mitra D. Mental stress in infertility: a tertiary care hospital-based study. Int J Reprod Contracept Obstet Gynecol 2018;7:4249-53. 